\title{
Bemerkung zu vorstehender Arbeit des Herrn Dr. Achelis.
}

Von

Fr. Kutscher.

(Der Redaktion zugegangen am 24. Oktober 1906.)

Von Herm Dr. Achelis war das Methylguanidin im menschlichen Harn aufgefunden worden, bevor es von Lohmann und mir mit anderer Methode darin ebenfalls nachgewiesen wurde. Durch einen Zufall hat siich die diesbezügliche Mitteilung im Zentralblatt für Physiologie außerordentlich verzögert, so daß unsere Angabe über das Vorkommen von Methylguanidin im Menschenharn in der Zeitschrift f. physiol. Chemie firüher erscheinen konnte. Ich bemerke dieses, um Herrn Achelis die zwweifellose Priorität seiner Beobachtung zu sichern. 